\title{
Radio Ads as a Strategic Offline Approach for Building Brand Awareness
}

\author{
Meral Ahmed Saeid ${ }^{1)}$ Prof. Dr. Rania Farouk Abdelazimm ${ }^{2)}$ Prof. Dr. Dina Gamal Abboud ${ }^{3)}$
}

1) Academic Researcher at Applied Arts Faculty, Helwan University. Egypt

2) Professor at Applied Arts Faculty, Helwan University. Egypt

3) Professor at Applied Arts Faculty, Helwan University. Egypt

KEY WORDS:

RADIO ADS, OFFLINE ADVERTISING, BRAND AWARENESS.

\begin{abstract}
:
The impact of online advertising can't be denied on building the brand awareness now days. Although Egypt considered one of the largest countries in terms of population that qualifies it to be a successful digital market However, there are many cultural, economic and technological constraints. With population exceeding 90 million high rates of illiteracy and low percentage of Internet users, meanwhile according to statistics of the ministry of information and communication, Compared to the population, There are still more than $50 \%$ of Egypt's population size cannot be accessed through online advertising (2018/2019), and it opens the door in front of offline advertising to be used more widely in Egypt to create the communication between the consumer and the brand and build the brand awareness. PROBLEM: Brand Awareness in Egypt faces some educational, technological and economical challenges, which requires finding another and different design solutions by reliance on Offline advertising instead, to achieve maximum brand awareness and engagement. Research aims to collect and study the role of radio ads as an offline advertising tool and how could be relied upon by designers to support brand awareness with the Egyptian market. METHODOLOGY An analytical study using a qualitative research, based on personal interviews with Advertising agency representatives discussing the strategy and methodology behind their relaunching offline campaign for the agency's Client Measuring the impact of Radio ads on a selected target audience.
\end{abstract}




\section{RESEARCH PROBLEM:}

Brand Awareness in Egypt faces some educational, technological and economical challenges, which requires finding another and different design solutions by reliance on Offline advertising instead, by which commensurate with the Egyptian market through direct communication with the public, especially when targeting a large number of consumers so as to achieve maximum brand awareness and engagement.

The problem is determined to answer the following questions:

1- How could designers rely on offline advertising in the digital age.

2- How Radio ad as an offline tool, offers design solutions that enhance brand awareness in Egypt.

\section{AIMS AND OBJECTIVES:}

Research aims to collect and study the role of radio ads as an offline advertising tool and how could be relied upon by designers to support brand awareness with the Egyptian market.

\section{HYPOTHESIS AND METHODOLOGIES:}

H1: Radio could build Brand awareness as a strategic Offline advertising channel.

$\mathrm{H} 2$ : Achieving high rate of brand awareness depends on benefit from the radio facilities such as repeated exposure, if we depend on the target audience group characteristics while designing the Radio ad and repeated to be top of mind and well recognized.

METHODOLOGY: An analytical study is using a qualitative research, has been conducted based on personal interviews with Ogilvy Advertising agency representatives (Aya Khaled- Senior Account Executive) and (Bassem Fahmy - Associate Creative Director) Cairo office on 20th January 2020, discussing the strategy and methodology behind the relaunching campaign for the agency's Client (CHEVRON - American multinational energy corporation) JUNE 2019, Measuring the impact of Radio ads on a selected target audience.

\section{RESULTS:}

This paper is an attempt to discuss the radio ads as offline tool by which could build brand awareness for the target audience. Highlighting the factors affecting the radio ad according to the literature; Reachability, portability, selective targeting, repeated exposure and memorability. The research also discusses how could the Radio ad reach high segment of the target group especially when communicating illiterate target audiences. Further research should be

done to different target groups aside drivers and class $\mathrm{C}$ to fulfil the points this research could not cover, could be on university undergraduate students in buses, targeting them while going to and back from the university at fixed times.

\section{INTRODUCTION:}

Now days, the Raise of technology and internet has changed and have impact on everything we interact with in our daily life (24). The modern marketing environment has changed extensively from what it was 10 years ago. In this changing environment, the brand awareness plays a crucial role for building the first impression of the brand. The brand awareness is changing the way modern Advertising environment focus on comprehensive knowledge about brands1. With growing internet users, more than 11 new users per second, which results in impressive total of one million users each day (20). While the Internet's impact on marketing is undeniable According to Internet World Stats, nearly 70 million Americans who can't be reached through online marketing efforts (33). According to the Local Market in Egypt, with a total population reaches near 100 Million (16), with $43 \%$ only Urban population, and 49\% internet penetration (19), six percent less than the percentage of the population living in urban areas within the country. Even though the arrival of the Internet appeared to be the end for traditional "Offline" mediums, Advertising campaigns using offline channels are still a fundamental aspect of many company's marketing mixes (33). Using Radio ads as offline advertising medium, one of the most accessible forms of media in the world today, despite the prevalence of the internet and the television (26).

Advertising is the activity by which the company communicates with the customer in order to familiarize them with new products or services through building brand awareness (Kotler 2002) (21)

\section{BRAND AWARENESS:}

Kotler (1997) stated that a brand is a name, term, symbol or design that is intended to identify the goods or services of one seller or group of sellers and the way it is used to differentiate these from those of competitors. (6) The American Marketing Association defined the brand as 'a name, term, sign, symbol, or combination that's designed to spot the products or services of one seller to differentiate them from those of competitors. (18) 
Building up a positive brand image depends on possessing high brand awareness, a well-established brand in the memory is easier for associations to be created and attached (Esch. et. all., 2006) (22) According to Keller (2008), Brand Awareness is the ability to identify the brand under different conditions (keller,2008) (7) which holds brand recognition and brand recall performance. (1) Brand awareness is essential for the communications process to emerge i.e., a top-of-the- mind awareness (Macdonald and Sharp, 2003; Netemeyer et al., 2004). (17)

Thwaites et al. (2012) found that a consumer who has a positive perception of the brand, will be tending to grow a greater motivation to purchase the product. (17) Brand awareness is one of the factors affecting the brand perception beside brand association, brand loyalty, brand image and brand equity based on guiding principle of Aaker (1991) Model (Fig.1).

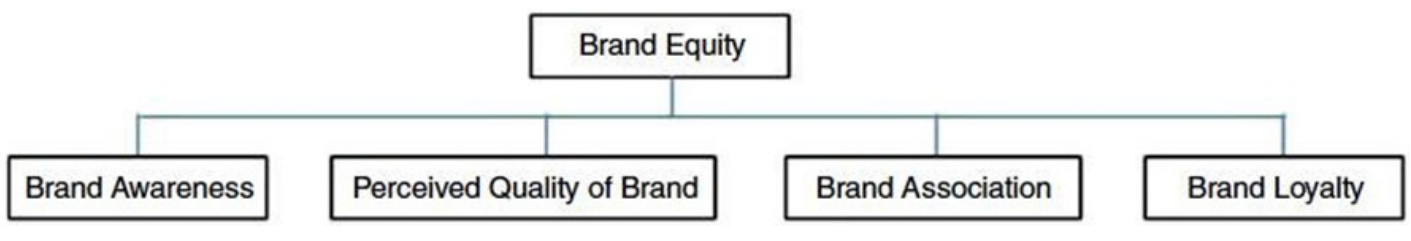

Fig (1): Aaker (1991) model

2.1 According to (Chakravarti et al., 2003) Brand awareness increases that a brand is going to be a part of the consideration when making a purchase decision. A necessary condition for consumers to have engagement with the brand is the presence of the brand in consumers' minds. The strength of the presence or mental node decides how easily different sorts of information can become attached to the brand (Keller, 2008).(7) Aaker (1991), differentiated (1) brand awareness into four different levels that are represented in below, which is called the awareness pyramid. These four different levels of the awareness pyramid help to build brand awareness about brands among consumers.

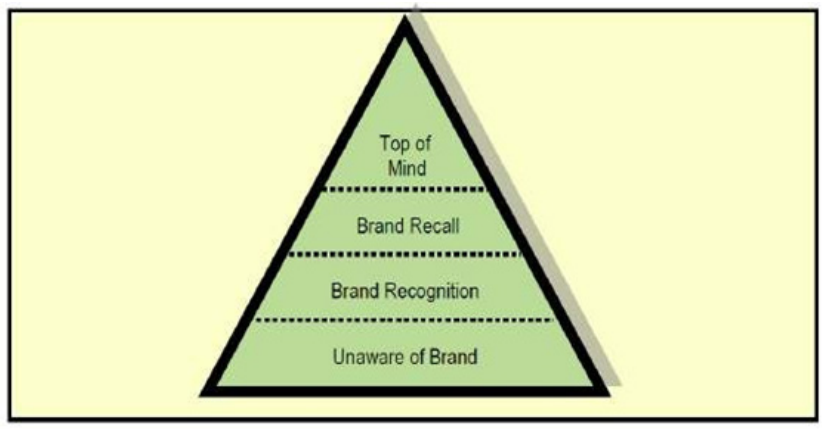

Fig (2): The Awareness Pyramid (Adapted from Aaker, 1991)

\subsection{MEASURING BRAND AWARENESS}

Brand awareness measures the accessibility of the brand in memory, often measured through brand recall or brand recognition. Brand recall reflects the power of consumers to retrieve the brand from memory. Brand recognition reflects the power of consumers to verify prior exposure to the brand. (4)

\section{OFFLINE ADVERTISING}

Radio as offline advertising tool has a special nature because of its ability to reach listeners anywhere, while they are doing other jobs and as a form of accompaniment that does not necessarily need concentration and follow-up. (30)

Offline Advertising is defined as "Using advertising resources of the real rather than the virtual - Online marketing world, like newspapers, billboards, flyers, radio and TV spots". Offline Advertising could be very effective, even for Internet marketers promoting their websites, especially when target local markets.

Offline marketing strategies utilize offline media channels to create awareness of a company's products and services. These campaigns can include radio and television in addition to print advertising - including billboards, signage, posters and Flyers, ads. (33)

Nowadays video is the leader in story media, radio is not dead. Radio have consistently proven to be one of the most effective advertising channels. (31) The average listener spends almost two hours daily listening to $\mathrm{AM} / \mathrm{FM}$ radio (typically during their commute). Radio is impactful for companies who may have target audiences in areas with low rates of Internet penetration. In such places, such as rural areas, radio tends to be extremely popular 


\subsection{RADIO ADS:}

Radio Advertising is a type of Offline traditional Advertising, using radio medium traditional stations as well as satellite and internet radio to advertise products and services. (8) Radio was the first broadcast medium used for family's entertainment to listen for the favorite radio programs. (10) Then, it played an important role in the communication with customers.

Where it can be used to advertise for 30-60 second spot as a separate ad. through or/in between shows.

\section{HISTORICAL OVERVIEW:}

Radio Ads. Is a story of innovation as a result of technology, Culture and social trends evolution. Starting from the 1900s, the idea of radio as a form of entertainment began to grow. (26)

Early Time in America 1922, the radio Advertising appeared (12) New York radio station WEAF run its first official paid radio Ad. In 1973, the first Radio Advertising appeared in UK. Birdseye Frozen food Ad. Was the first to launch with London Broadcasting Company Launch - The First commercial station in the country. (14) Radio Golden Age was full of countless advertisers and sponsored programs. Regarding Egypt, With the most powerful and extensive broadcasting system in the Arab region, Started officially in Egypt May 1934. (23). The first Commercial Radio Channel in Egypt was the Middle East Radio started to communicate Ads. Due to the introduction of private FM radio stations (NOGOOM FM 100.6 all Arabic music format all western music station - NILE FM 104.2) broadcasting 24 hrs a day, a massive raise in radio advertising industry. (23)

\section{REASONS FOR RADIO ADS. DEVELOP- MENT:}

(Harvey, Steve) mentioned that it isn't true that radio advertising might to be abandoned as a result of the dominance of internet and different innovative advertising platforms. (10) Radio advertising challenges and opportunities still exist. Companies were looking for a way to reach more customers. Despite countless evolutions in digital marketing, radio continues to be one of the most valuable methods of advertising - reaching 93\% of adults each week in the US. The ability of radio to reach listeners while the doing other jobs with simple message gave it a special nature. (30) Out of all users listening to Radio ads vs other types of ads $59 \%$ more likely to remember the slogan of the Ad. Campaign - $10 \%$ more likely to recall the advertiser with $9 \%$ higher brand awareness (27). As a result of the development of radio as a medium for advertising, the advertising opportunities have been changed too, became subjective and customizable depending on the brand needs. Regarding the Egyptian market, with total population reaches near 100 Million (16), with $43 \%$ only Urban population, and $49 \%$ internet penetration, Radio ads as offline advertising medium, one of the most accessible forms of media Egypt today. Several private pop radio stations such as Nile FM, Nogoum FM, Mega FM, Nagham FM, DRN , NRJ who already have a large youth following, and can be tapped to reach and influence this segment of the population. Shaaby FM which targets different segment of the Egyptian population.

\section{RADIO ADS AS A STRATEGIC AWARE- NESS TOOL FOR BRANDS}

No doubt Television and digital media have a part to play in marketing world, but radio has an impact on the consumer world that simply can't be matched (13). Sitting in car, or waiting to get home on the train, the radio is always there to come to the rescue. radio advertising offering companies a near real-time way to reach their target audience.

Today, radio is available across multiple platforms (26). Generation $X$ that listen to the radio, but a wide spread of cultural generations ranging from the baby boomers right through to the millennials Beside streaming traditionally, can be streamed live online on the Internet or through mobile applications. Radio advertising is inexpensive compared to TV advertising and can support printed advertising by mentioning printed advertisements. Thus, there is a double benefit. Radio advertising, according to Kelley, Jugenheimer, 
and Sheehan (2011). Added, radio advertising can make excellent use of slogans, music, and sound effects (p. 134). (28)

\subsection{TYPES OF Radio Advertising (3):}

\section{a. The live read}

- Type of Ad. more effective with a really popular on-air host giving weight to the show audience.

b. The Jingle ad

Is a short, catchy song about company, can be funny, serious, or informative telling listeners where to find your business or your products

c. The sponsored ad

- Many radio stations implement sponsorships for certain types of radio segments, such as traffic, weather, or sports scores during halftime of the big game. It will generally sound something like this: 'This hour's weather update brought to you by Pepsi.

\subsection{Reasons of Radio Advertising Usage - Ad-} vantage Radio advertising remains one of the most reliable marketing option. Providing reach, flexibility, and an opportunity to connect with customers on a deeper, more emotional level.

\subsubsection{REACHABILITY}

More, in the digital age, radio advertising is still having a high effect.

(5) According to the Nielsen research brand, radio holds a higher weekly audience than television, and $93 \%$ of adults listen to the radio each week. They're not just listening through traditional means and connecting via streaming platforms Anghamy and Spotify and different Radio Online apps.

6.2.2 PORTABILITY Radio is the only mass medium that people use while driving, clean the house or doing any other job. (9)

\subsubsection{SELECTIVE TARGETING Each radio} station could target specific demographics and market segments. These are usually defined by the programming, type of music being played, the on-air personality, and what time of the day the advertising will run. (2)
Example: McDonald's targeting people going back home after work - rush hours. Aired (2018) Announcing the drive through service. Radio Ad. depending on talking with the listeners.

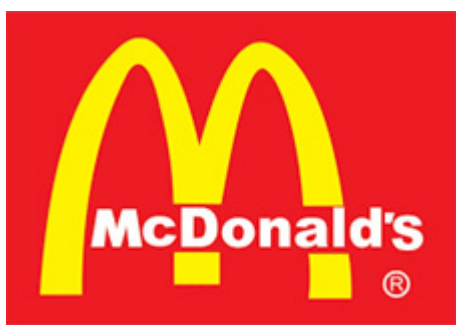

Fig (3): McDonald's LOGO

VO: That feeling, when you get staked in your car, dreaming of McDonald's Sunday ice-cream, and you can't get out of your car, Sure you are late, in a hurry and can't find a place to park your car Demo: McDonald's Drive through service order - Eat - without getting out of your car.

McDonald's... Nothing can stop you. After all, the listener can picture himself in that scenario while being already in the car, back home from work and consider the brand while making decision.

\subsubsection{REPEATED EXPOSURE}

Radio depends on repetition, known as frequency of message to be affective and create awareness. It takes 3 times hearing a spot before you assume it, recognize it, and consider the product or the service (2)

\subsubsection{MEMORABILITY}

According to researchers, sound can be stored effectively inside memory for longer than visuals, Especially, when it comes to jingles. The right music and lyrics in the jingle can create a high emotional and awareness connection between the listener and he brand.

\section{Examples:}

a. El Arousa TEA (teshrab eh ... ashrab shay) What you want drink? Tea.

Beside airing the ad. On TV you can listen to the jingle every day on Radio where you automatically whenever one asking you - What do you want to Drink? - you reply completing the sentence 
spontaneously - I want tea, even If you going to ask for other drink. With End demo - EL Arousa TEA - The Egyptians Choice.

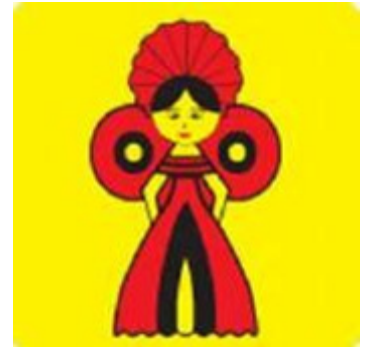

Fig (4): El Arousa Tea Logo

b. Coca-Cola Bet2olha ezay - (How do you say it?)- March 2019

For solving the problem that any one asking for dark Soda drink (Pepsi / Coca-Cola) he says Pepsi please, even if he means Coca-Cola. Repeating Coca-Cola word along the song with different singers and music

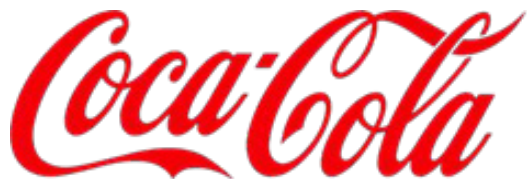

Fig (5): Coca-Cola Logo

7. AWARENESS CAMPAIGN EXAMPLE: LOUVRE ABU DHABI HIGHWAY GALLERY Nov. 11th 2018, Abu Dhabi louvre museum opened as the first universal museum in the Arabian world. To encourage local audiences that this museum is far from, boring, they set un-traditional campaign using Offline traditional Advertising tools (Outdoor/ Radio)(32) with more than 12,000 people drive everyday through Abu Dhabi highway road while listening to radio. Using the highway road to create road museum (Highway Gallery) in partnership with Abu Dhabi Media Company. (25)

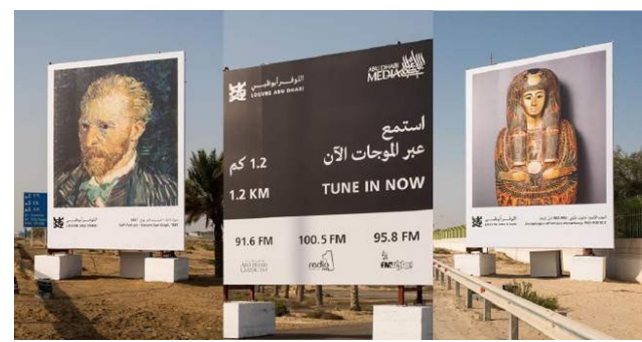

Fig (6): Abu Dhabi Road Highway gallery
Once approaching the billboards, drivers turn the radio into $100.5 \mathrm{FM}, 91.6 \mathrm{FM}, 95.8 \mathrm{FM}$ the music interrupted by museum audio guide spot lasts for 30 seconds. bringing life to the outdoors through the radio spots creating high rate of awareness for the listeners about the museum encouraging them to consider the visit through telling the listeners more information about the paint billboards. (25)

\section{RESEARCH METHODOLOGY:}

A qualitative research has been conducted, based on personal interviews with Ogilvy Advertising agency representatives (Aya Khaled- Senior Account Executive) and (Bassem Fahmy - Associate Creative Director) Cairo office on 20th January 2020, discussing the strategy and methodology behind the relaunching campaign for the agency's Client (CHEVRON - American

multinational energy corporation) JUNE 2019 (15). The interview with Aya concentrated on the client's brief, Aya said "CHEVRON was relaunching their DELO CALTEX (Truck\& buses DIESEL ENGINE OIL), but with a current problem that after their exit in 2011 from the Egyptian market as (Gas station), gas and oil provider; with a lack of awareness towards the existence and availability of their products at the authorized distributers all over Egypt". The interview with Bassem concentrated on the design thinking to get the right strategy through a creative framework to work on. He said "Based on a research from the client Service department conducted on a sample of the drivers representing the target group, testing their preferences, taste of music, advertising medium channels they exposed to. We found that the most listened music type to their taste is the Popular Music called (MAHRAGANAT) through the radio or by their own". He continued saying "Depending on that, for targeting them and create brand awareness and a connection between the brand and the targeted group; worked in two aligned directions creating Key Visual including the DELO Caltex product pack, to build awareness with the product shape, and a Radio ad song communicating that DELO OIL product 
produced by CALTEX, Through a simple slang lyrics mixed with their taste of music to be aired through the radio channels they tend to listen in between the radio shows they interact with, targeting the time they listen to this radio channels at night while driving.

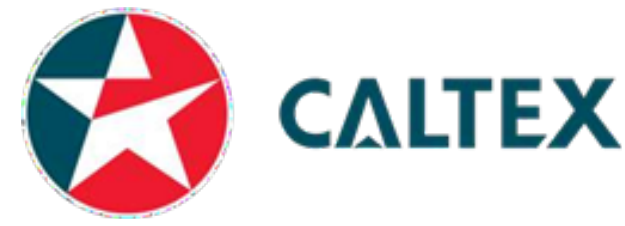

Fig (7): Caltex Logo - American oil Brand

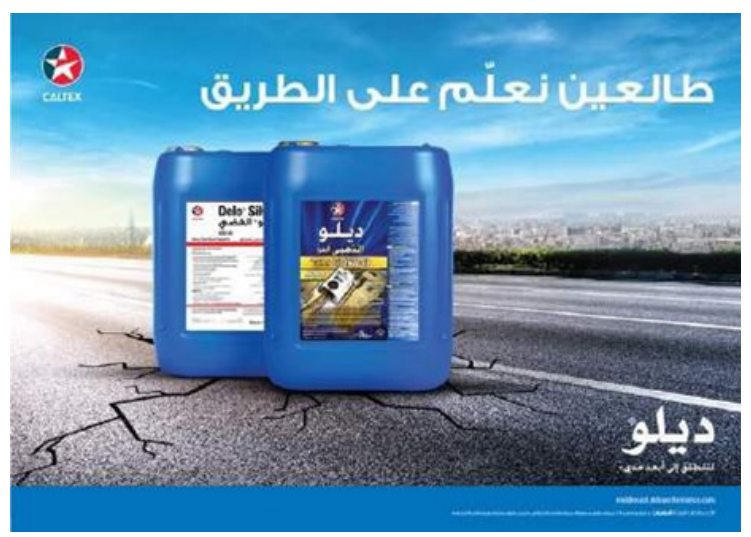

Fig (8): Caltex- Campaign Key Visual
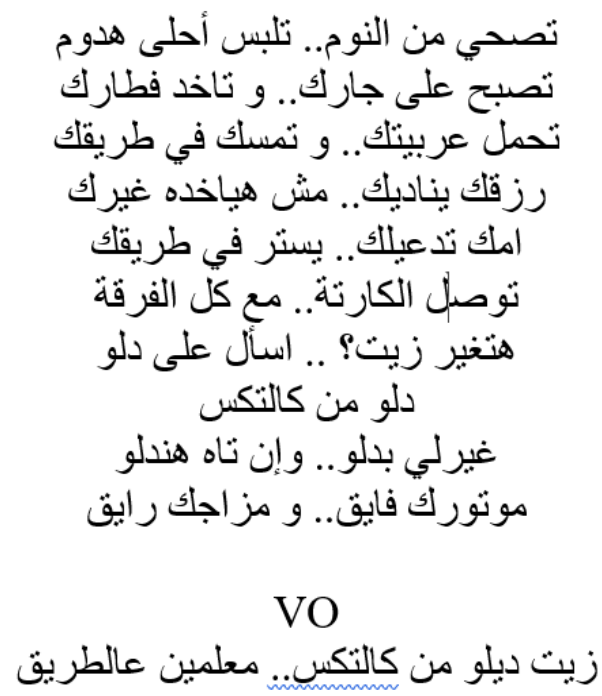

Fig (9): Caltex RADIO Ad Lyrics - Ogilvy 2019

Accordingly, A quantitative study based on the previous information and according to the scale (Basic AIDA model) (29) measuring brand awareness through Awareness $\rightarrow$ Interest $\rightarrow$ Desire $\rightarrow$
Action

A phone call survey is done with a segment of the target audience - total number of 37 Truck/ Lory driver (Due to the lack of education for the target group that may be an obstacle in filling a written / Online questionnaire) as a confirmatory study to measure the effectiveness of radio ads and posters done for this campaign. The researcher asked the drivers prepared questions orally and their answers were collected and recorded for further analysis.

\section{HYPOTHESIS:}

H1: Radio could build Brand awareness as a strategic Offline advertising channel.

$\mathrm{H} 2$ : Achieving high rate of brand awareness depends on benefit from the radio facilities such as repeated exposure, if we depend on the target audience group characteristics while designing the Radio ad and repeated to be top of mind and well recognized.

\section{FINDINGS AND DISCUSSION}

Table presents the distribution of the respondents' answers. Out of 37 respondents $72 \%$ were like to recall the brand name immediately and $18 \%$ to recall it after a while, and 75\% more likely to memorize the ad. $81 \%$ of the targeted group to recall the lyrics with a higher rate of $94 \%$ to memorize the music tempo, and with $85 \%$ consider purchasing and $100 \%$ likability for the Radio ad. This means that this survey conducted on the required target group who were more likely to be aware of the brand as a result of the repeated exposure to the Radio ad.

Building on the questionnaire survey done with 37 Truck/ Lory driver on phone and analyzed according to the scale (Basic AIDA model), results shown in the following table: 


\begin{tabular}{|l|c|c|c|c|c|c|}
\hline & $\begin{array}{c}\text { Brand } \\
\text { name } \\
\text { recall }\end{array}$ & $\begin{array}{c}\text { Ad } \\
\text { memorability }\end{array}$ & $\begin{array}{c}\text { Lyrics } \\
\text { recall }\end{array}$ & $\begin{array}{c}\text { Music } \\
\text { Tempo } \\
\text { memorability }\end{array}$ & $\begin{array}{c}\text { Consideration } \\
\text { to purchase }\end{array}$ & Likability \\
\hline Immediately & $\mathbf{2 7}$ & $\mathbf{2 8}$ & $\mathbf{3 0}$ & $\mathbf{3 5}$ & - & - \\
\hline $\begin{array}{l}\text { After a } \\
\text { while }\end{array}$ & $\mathbf{7}$ & $\mathbf{5}$ & $\mathbf{3 5}$ & $\mathbf{2}$ & - & - \\
\hline $\begin{array}{l}\text { Took more } \\
\text { than 10 sec. }\end{array}$ & $\mathbf{3}$ & $\mathbf{4}$ & $\mathbf{2}$ & - & - & \\
\hline & & & & & & \\
\hline
\end{tabular}

Table (1) : Questionnaire results following Basic AIDA MODEL

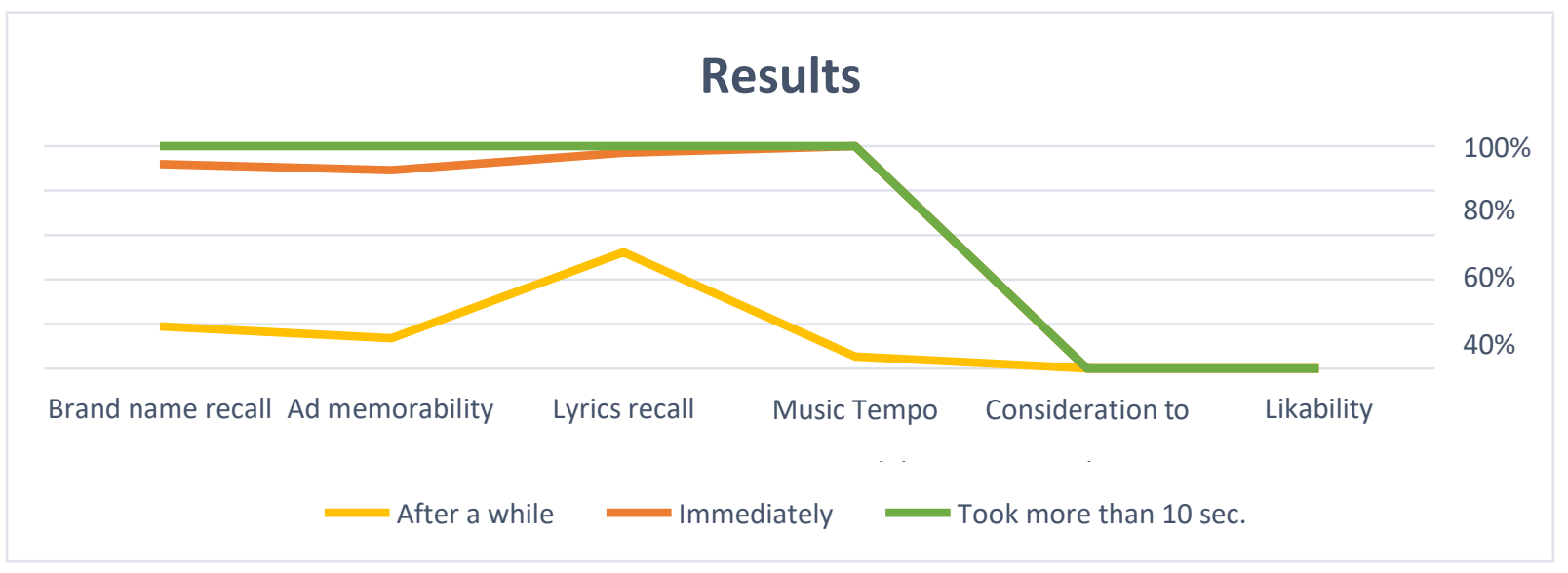

Fig (10): Shows the result of the study.

\section{CONCLUSION AND RECOMMENDATIONS:}

This paper is an attempt to discuss the radio ads as offline tool by which could build brand awareness for the target audience. Highlighting the factors affecting the radio ad according to the literature; Reachability, portability, selective targeting, repeated exposure and memorability. The research also discusses how could the Radio ad reach high segment of the target group especially when communicating illiterate target audiences. Recommendation: Further research should be done to different target groups aside drivers and class $\mathrm{C}$ to fulfil the points this research could not cover, could be on university undergraduate students in buses, targeting them while going to and back from the university at fixed times over Egypt's roads.

\section{RESULTS}

This paper is an attempt to discuss the radio ads as offline tool by which could build brand awareness for the target audience. Highlighting the factors affecting the radio ad according to the literature; Reachabili- ty, portability, selective targeting, repeated exposure and memorability. Using Offline advertising tools as RADIO ads, could have a high effect on raising brand awareness in Egypt specially when targeting illiterate target audience.

\section{REFERENCES}

1. Author Team Linchpin (2019) "How to effectively use radio advertising to grow small business" published in Radio \& TV on December 9, 2019 accessed on January 2020. Online retrieved from https://inchpinseo.com/guide-to-radio-advertising/

2. Bryce, S. "What is Radio Advertising". Retrieved from <" https://study.com/academy/lesson/what-is-radio- advertising-definition-types-examples.html $>$ Accessed on December 24th,2019

3. Chandon, Pierre (2003) "Note on Measuring brand awareness, Brand Image, Brand Equity and Brand Value" Online from https://flora.insead.edu/fichiersti_wp/inseadwp2003/2003-19.pdf

4. Colling, Bryan (2018) "Unique advantages of radio advertising" https://collingmedia.com/radio- advertising/unique-advantages-of-radio-advertising/

5. Crawford, Gary (2009) "The SAGE Dictionary of Leisure 
Studies - Chapter Branding, Brand Awareness and Brand Image" Published 2009 - London-Accessed January 17th, 2020

6. Dennhardt S. (2014) "The Impact of User Interactions in Social Media on Brand Awareness and Purchase Intention: The Case of MINI on Facebook". In: User-Generated Content and its Impact on Branding. Springer Gabler, Wiesbaden Retrieved from $<$ https://08102e0zz-1105-y-https-link-springercom.mplbci.ekb.eg/chapter/10.1007/978-3-658-02350-8_9 $>$

7. EVOLUTION OF RADIO BROADCASTING - online retrieved from https:/opentext.wsu.edu/com101/chapter/7-2-evolution-of-radio-broadcasting/ Accessed on 16th January 2020

8. Gail Jordan, "Advantages and disadvantages of offline advertising" online retrieved from on 20th January $2020 \mathrm{http} / /$ tinobusiness.com/6-advantages-and-disadvantages-of-radio-advertising/

9. Harvey, Steve "The history of radio advertising: marketing with volume" Online Retrieved from https://radiofidelity. com/history-of-radio-advertising/ Accessed on 23rd January 2020

10. Hetherington, Sue (2018) "10 Golden benefits of radio advertising"https://www.radioresults.com.au/blog/benefits-of-radio-advertising published July 2018 Accessed on 18th Jan. 2020 11:00 am

11. History of Radio Advertising Chapter $1 /$ Lesson 22 published on 10 September 2017, Online Retrieved from

12. <http://study.com/academy/lesson/history-of-radio-advertising >. 12- Online, https://radiofidelity.com/history-of-radio-advertising/

13. https://theempire.com/radioadvertising/uae/?utm_ter$\mathrm{m}=\% 2 \mathrm{Bradio} \% 20 \% 2$ Badvertising\&utm_campaign $=\mathrm{GSN}+$ -

14. +Radio+Advertising $+(\mathrm{UAE}) \&$ utm_source $=\mathrm{ad}-$ words\&utm_medium $=$ ppc\&hsa_acc $=5199419397 \&$ hsa_cam $=69 \overline{4} 0923336 \& \mathrm{hsa}$ grp $=78717619614 \& \mathrm{~h}-$ sa_ad=390319078295\&hsa_src=g\&hsa_tgt=kw d - $19534925171 \& \mathrm{hs}$ a_kw $=\% 2 \mathrm{Bradi} \% 20$ $\% 2$ Badvertising \&hsa $\mathrm{mt}=\overline{\mathrm{b}} \& \mathrm{hsa}$ net $=$ adwords $\& \mathrm{~h}-$ sa_ver $=3 \&$ gclid $=\mathrm{Cj} 0 \quad-\quad$ KCQiAyKrxBRDHARIsAKCzn8xyySE6yZrxCPPTDyM_Onf2UvE1zoyOWT4iALU618nVoXOPF188vkIaAh o2EALw wcB Accessed 25th January $2020 \mathrm{https} / /$ www.caltex.com/ph/motorists/products-and-services/lubricants/delo-trucks-buses/diesel-engine-oils.html

15. https://www.capmas.gov.eg/ Accessed on 24th January 2020

16. Jumiati Sasmita Norazah Mohd Suki , (2015),'YYoung consumers' insights on brand equity", International Journal of Retail \& Distribution Management, Vol. 43 Iss 3 pp. 276 $292 \mathrm{https}: / /$ www.academia.edu/25524670/Young_consumers_insights_on_brand_equity_Effects_of_brand_associati on_brand_loyalty_brand_awareness_and_brand_image accessed on December 27th 2019

17. Keller, Kevin Lane "Handbook of marketing "- Chapter 8: Branding and Brand Equity - Edited by Barton A. Weitz \& Robin Wensley-Retrieved from< http://08113e2j1.1105.y.http.sk.sagepub.com.mplbci.ekb.eg/reference/ hdbk marketing/n8.xml?fromsearch=true

18. Kemp̄, Simon (Egypt Digital 2019) LinkedIn slide share -
Online Retrieved from https://datareportal.com/reports/digital-2019-egypt Published January 31st 2019, Accessed on June 6th, 2019

19. Kemp, Simon (Global internet use accelerates) 2019-Online https://wearesocial.com/blog/2019/01/digital- 2019-global-internet-use-accelerates Published on 30th January 2019, Accessed on 6th June 2019.

20. Kotler,P.(2002). (Marketing management millennium edition) - New Jersey.

21. laiho, maiju (2012) "Brand image and brand awareness case study" department of marketing, school of business and engineering

22. Media Landscapers (2019) - European Journalism Center https://medialandscapes.org/country/egypt/media/radio Accessed on January 18th, 2020.

23. Nakhil, Rania Farouk AA. "Understanding Brand loyalty from the Consumer perspective: An exploratory study targeting Social networking services in Egypt." Journal of architecture and art 14 (2019).

24. Natividad, Angela (2018) “ Louvre Abu Dhabi uses billboards and radio to give high way gallery tours" https:// www.adweek.com/creativity/louvre-abu-dhabi-uses-billboards-and-radio-to-give-highway-gallery-tours/ Accessed on Sunday 30 December 2018

25. Noone, Louise (2013) - "Radio In Digital Age" MSc. Interactive Digital Media- University of Dublin.

26. Published March 2013

27. Online Website: https://adage.com/ Accessed 23 Accessed on 4th January 2020

28. Potdar, Y. A. (2013). Comparison of media selection in the U.S. and Indian advertising industries (Order No.1535400). Available from ProQuest Dissertations \& Theses Global. (1346016871). Retrieved from https://search.proquest.com/ docview/1346016871?accountid=178282 Priyanka, R., "AIDA Marketing Communication Model: Stimulating a purchase decision in the minds of the consumers through a linear progression of steps," International Journal of Multidisciplinary Research in Social Management, Vol. 1, 2013, pp 37-44 Retrieved from< http://08113e0zu.1105.y.http. sk.sagepub.com.mplbci.ekb.eg/reference/the-sage-dictionary-of- leisure-studies/n26.xml>

29. Shams, Dalia (2019) "Egypt through its advertisements" Online retrieved from http://english.ahram.org.eg/NewsContent/1/4/338083/Egypt/Media/Egypt-through-its-advertisements.aspx - Saturday 20 July 2019 Accessed 15th January 2020 3:45 am

30. Thrive (2017) "Methods of Offline marketing and advertising" Online Retrieved from" https://thrivehive.com/methods-of-offline-marketing-and-advertising/ Accessed on December 2019

31. Unknown (2018) "High way gallery by TBWA / RAAD" https://www.thedrum.com/creative-works/project/tbwaraadlouvre-abu-dhabi-louvre-abu-dhabi-highway-gallery March 2018

32. Unknown, (Offline Marketing) - Retrieved online https:// www.marketing-schools.org/types-of-marketing/offline-marketing.html - Accessed on 12th 2019 